\title{
3D Computational Simulation of Calcium Leaching in Cement Matrices
}

\author{
J.J. Gaitero ${ }^{\mathrm{a}} \bowtie$ J.S. Dolado ${ }^{\mathrm{a}}$, C. Neuen ${ }^{\mathrm{b}}$, F. Heber ${ }^{\mathrm{c}}$, E.A.B. Koenders ${ }^{\mathrm{d}}$ \\ a. Tecnalia (Derio, Vizcaya, Spain) \\ b. Fraunhofer-Institute for Algorithms and Scientific Computing SCAI (Sankt Augustin, Germany) \\ c. University of Bonn-(Bonn, Germany) \\ d. Delf University of Technology-(Delft, Netherlands) \\ \juanjose.gaitero@tecnalia.com
}

Received 16 October 2013

Accepted 28 March 2014

Available on line 15 October 2014

\begin{abstract}
Calcium leaching is a degradation process consisting in progressive dissolution of the cement paste by migration of calcium atoms to the aggressive solution. It is therefore, a complex phenomenon involving several phases and dissolution and diffusion processes simultaneously. Along this work, a new computational scheme for the simulation of the degradation process in three dimensions was developed and tested. The toolkit was used to simulate accelerated calcium leaching by a $6 \mathrm{M}$ ammonium nitrate solution in cement matrices. The obtained outputs were the three dimensional representation of the matrix and the physicochemical properties of individual phases as a consequence of the degradation process. This not only makes it possible to study the evolution of such properties as a function of time but also as a function of the position within the matrix. The obtained results are in good agreement with experimental values of the elastic modulus in degraded and undegraded samples.
\end{abstract}

KEYWORDS: Cement paste; Microstructure; Modelization; Durability; Transport properties

Citation / Citar como: Gaitero, J.J.; Dolado, J.S.; Neuen, C.; Heber, F.; Koenders, E.A.B. (2014). 3D Computational Simulation of Calcium Leaching in Cement Matrices. Mater. Construcc. 64 [316], e035 http://dx.doi.org/10.3989/ mc.2014.08813.

RESUMEN: Simulación computacional en 3D del lixiviado de calcio en matrices de cemento. El lixiviado de calcio es un proceso de degradación consistente en la disolución progresiva de la pasta de cemento por la migración de los átomos de calcio a la disolución agresiva. Se trata por tanto de un fenómeno complejo que involucra simultáneamente diferentes fases y procesos de disolución y difusión. En este trabajo se desarrolló y probó una nueva herramienta computacional para la simulación del proceso de degradación en tres dimensiones. Para ello se simuló el lixiviado de calcio acelerado provocado por una disolución de nitrato amónico $6 \mathrm{M}$ en matrices de cemento. Como resultado se obtuvieron la representación tridimensional de la matriz y las propiedades físico-químicas sus fases a lo largo del tiempo. Esto permitió estudiar la evolución de dichas propiedades a lo largo del proceso de degradación así como en función de su posición dentro de la matriz. Los resultados obtenidos coinciden con los valores experimentales del módulo elástico tanto de muestras degradadas como intactas.

PALABRAS CLAVE: Pasta de cemento; Microestructura; Modelizacion; Durabilidad; Propiedades de transporte

Copyright: (C) 2014 CSIC. This is an open-access article distributed under the terms of the Creative Commons Attribution-Non Commercial (by-nc) Spain 3.0 License. 


\section{INTRODUCTION}

Calcium leaching of the cement paste is a degradation process consisting in progressive dissolution of the cement paste as a consequence of migration of calcium ions to the aggressive solution. It is therefore a typical example of a dissolution process in a porous matrix where some of the mineral phases of the paste dissolve in the interstitial pore solution. The kinetics of the process is therefore controlled by coupled dissolution and diffusion processes. The degradation rate depends to a great extent on the nature of the aggressive solution. Under natural conditions, such a solution is generally water with low ion content. However, water is replaced in some experimental works by a more aggressive solution such as $6 \mathrm{M}$ ammonium nitrate $(1,2)$, since under such conditions the dissolution processes can take place in a reasonable experimental time scale. Computationally speaking, the employment of aggressive solutions is also appealing in order to shrink down the length scale $(L)$ under which the rate of calcium leaching is much faster than the rate of transport and the so-called Local Chemical Equilibrium (LCE) condition begins to apply. Applying the dimensional analysis made by Barbarulo et al. (3) to the case of accelerated calcium leaching process, the length scale required to fulfill the LCE condition is $L \sim 200 \mathrm{~nm}$; whereas for the not accelerated processes $L \sim 20 \mu \mathrm{m}$. Thus, in contrast to what happens with non accelerated counterparts, in the case of accelerated calcium leaching processes the simplifying LCE condition is satisfied at length scales which still enable the study of the impact at the C-S-H level.

Apart from the calcium loss, the main effect of calcium leaching is the porosity increase of the matrix. The reason for this is the progressive degradation of most phases. However, each of them loses calcium by means of very different mechanisms. For instance, portlandite dissolves completely in the aggressive solution leaving a hole/pore in its place. By contrast, the C-S-H gel undergoes a porosity increase in the range of gel porosity maintaining some of its structural characteristics. In both cases there is a reduction of the mechanical performance of the paste that can be measured in terms of compressive strength and elastic modulus.

Several attempts have been made to model calcium leaching of cementitious materials $(1,4-13)$. One of the difficulties for doing so arises from the multi-phase nature of the cement matrix, since the mechanism of calcium loss and the equilibrium calcium concentration are different for each of these phases. As a consequence, they have different dissolution rates depending mainly on their calcium to silicon ratio (7). The most common approaches to overcome these difficulties consist on either limiting the number of phases considered or using a continuous equilibrium formulation based on Berner's diagram (14). The values of average porosity, strength and velocity of the degradation front provided by these models are reproduced well by experimental results.

The objective of this work was the development of the necessary tools to simulate, in three dimensions, calcium leaching of the cement matrix at the level of the nano/microstructure. This includes the construction of a cement matrix microstructure affected by various parameters, such as the mineralogy of the cement and the water to cement ratio, followed by the degradation of the individual phases making up the cement matrix. Since the characteristic length scale of cement hydrates is in the range of nanometers the spatial resolution of the code had to be adjusted accordingly.

\section{BASICS OF THE MODEL}

\subsection{Construction of the matrix}

The construction of the cement matrix was carried out using an updated version of Hymostruc 3D (15). This program simulates cement hydration and formation of structure in Hardening-Cement-Based materials. The input data are the water to cement ratio, some physicochemical properties of the cement, some geometrical considerations (dimensions of the structure, number of voxels, etc.) and certain information about the hydration products (size of portlandite particles, calcium to silicon ratio of the gel, etc). Hymostruct 3D allows the simulation in solely a few minutes of hydration processes lasting from a few hours to several months. The resulting matrix is presented in the form of a cube with a size of up to $100 \mu \mathrm{m}$. Once the structure is created, it has to be divided in voxels to introduce it in the degradation program. The number of voxels per micron can be varied between 1 and 20 with the processing time and the size of the output files varying accordingly. The nature of each voxel is predetermined by the variety of phases considered not being possible to have more than one phase per voxel. In addition, all voxels of the same nature are exactly identical with the same chemical composition, porosity and density. This approximation may seem a bit rough for a non-crystalline phase like the C-S-H gel which does not possess a fix stoichiometry and structure. Nevertheless, three different C-S-H varieties have been considered to soften it.

\subsection{Degradation code}

\subsubsection{Basic concepts}

For the implementation of the degradation code five reactive phases were considered: portlandite, unhydrated clinker and three types of C-S-H gel: inner 
product (IP-CSH), outer product (OP-CSH) and overlapping (OL-CSH). As it was mentioned before, in all cases the loss of calcium results in an increment of porosity; however, due to their different nature each of them has to be considered separately.

The degradation of portlandite is described solely as a dissolution process that involves the migration of ions from the solid phase to the aggressive solution. Since the volume of the voxels is fixed, the loss of calcium results in an increase of the porosity of the voxel which can be calculated using the value of the bulk density of portlandite, $2.27 \mathrm{~g} / \mathrm{cm}^{3}$.

The three C-S-H gel varieties were described by an extended Tobermorite-Portlandite model (16-18). The extension consisted in assuming that instead of having only part of the calcium in the form of portlandite, all the calcium of the gel was in the form of portlandite. This assumption implies that the dissolution of a similar amount of calcium in portlandite and C-S-H gel results in exactly the same porosity increase. According to the aforementioned models, this might be the case for values of the calcium to silicon ratio larger than 0.83 (the value for tobermorite) but there is no reason why this should hold for lower values. Since the only difference between the three C-S-H phases was the initial porosity obtained from Hymostruc 3D, and subsequently the density, these approximations are equally valid for all of them.

A similar but more complex approach was used for the description of the clinker. In this case, two different situations were envisaged depending on the calcium concentration of the voxel. When such concentration is greater than the calcium concentration of the undegraded C-S-H gel, clinker loses calcium without any porosity increase. On the contrary, once this threshold value is reached, clinker voxel transforms into an IP-CSH voxel with no porosity and degrades exactly in the same way as all gel voxels. This method intends to simulate the simultaneous hydration and degradation processes that take place in the surface of clinker grains. As the aggressive solution reaches a clinker grain, calcium begins to dissolve as it would do during the pre-induction period of the hydration process. However, using $6 \mathrm{M}$ ammonium nitrate as aggressive solution, it is possible to assume that calcium solubility is large enough to prevent portlandite's precipitation. On the contrary, C-S-H gel's solubility depends on its calcium to silicon ratio. Therefore, it seems reasonable to think that locally calcium concentration in the solution in direct contact with the clinker will be large enough to allow the precipitation of C-S-H. Of course, the calcium to silicon ratio of the gel depends on the calcium concentration of the surrounding solution. In addition, since C-S-H gel's density is lower than clinker's density, it is possible to assume that there is a net calcium loss from the solid phase without any increase of porosity. Only once all the clinker of the voxel has transformed into CSH gel, the porosity can increase as a consequence of the degradation of the gel.

\subsubsection{Mathematical Representation}

With the whole degradation process being explained solely in term of the dissolution of calcium, the only possible chemical reaction was [1]

$$
2 \mathrm{NH}_{4} \mathrm{NO}_{3}+\mathrm{Ca}(\mathrm{OH})_{2} \rightarrow \mathrm{Ca}\left(\mathrm{NO}_{3}\right)_{2}+2 \mathrm{NH}_{3}+2 \mathrm{H}_{2} \mathrm{O}
$$

As a consequence, only three different species need to be present in the pore solution: ammonium nitrate, calcium hydroxide and calcium nitrate. The parameter that governs diffusion of each of these species in a particular media is the diffusion coefficient. In this work, the diffusion coefficients were assumed to be [2]:

$$
D=D_{\text {Bulk }} \times P
$$

Where $D_{B u l k}$ is the bulk diffusion coefficient of a given chemical species in bulk water. The values of $D_{B u l k}$ were obtained from the experimental values available in the literature (19). $P$ is the relative porosity of the phase, with a value of one when the voxel is part of a capillary pore. Initially, all voxels containing a particular phase have the same porosity and therefore the same diffusion coefficient. However, as soon as the degradation process begins, porosity can vary considerably from voxel to voxel and so does the diffusion coefficient.

Due to the aforementioned aggressiveness of the solution, the timescales of the transport and chemical processes differ by several orders of magnitude. Therefore, transport and reaction decouple, so that the Nernst-Planck equation is used to describe the transport, and a direct reaction model to account for the chemical reactions. Consequently, the aggressive solution has to enter the voxels containing hydration products in order to degrade them. The (Poisson-) Nernst-Planck equation system has the form [3-4].

$$
\begin{gathered}
\nabla\left(D_{i}(x) \nabla u_{i}(x, t)+\frac{z_{i} F}{R T} \nabla \phi(x) u_{i}(x, t)\right)=\frac{\partial u_{i}(x, t)}{\partial t} \\
\sum_{i} z_{i} u_{i}(x)=\Delta \phi(x)
\end{gathered}
$$

Where $u_{i}$ is the concentration, $D_{i}$ is the diffusion tensor, $\phi$ the electrical potential, $z_{i}$ the ion charge number, $F$ the Faraday constant, $T$ the temperature and $R$ the ideal gas constant. We start with the assumption that due to the length scale considered and since no outer electric field will be present there is no charge splitting to be expected and species are 
regarded without explicit dissociation, thus making each species charge neutral. Since the solution of the Poisson Equation is now always trivial, the transport operator of the three species may be split and the resulting smaller systems can be solved much faster than one combined system.

The implementation of the transport is then carried out via a finite element method, rewriting the differential equation into its weak form regarding its space discretization and using an implicit Euler scheme to advance time [5-7].

$$
\begin{aligned}
& \int_{\Omega} \nabla\left(D_{i}(x) \nabla u_{i}(x, t)+\frac{z_{i} F}{R T} \nabla \phi(x) u_{i}(x, t)\right) v_{j}(x) d x \\
& =\int_{\Omega} \frac{\partial u_{i}(x, t)}{\partial t} v_{j}(x) d x, \forall \mathrm{v}_{j} \in \mathrm{H}_{1}(\Omega)
\end{aligned}
$$

$$
\begin{aligned}
& \int_{\Omega}\left(D_{i}(x) \nabla u_{i}(x, t)+\frac{z_{i} F}{R T} \nabla \phi(x) u_{i}(x, t)\right) \nabla v_{j}(x) d x \\
& \quad=\int_{\Omega} \frac{\partial u_{i}(x, t)}{\partial t} v_{j}(x) d x, \forall v_{j} \in \mathrm{H}_{1}(\Omega) \\
& \quad \int_{\Omega}\left(u_{i}\left(x, t_{n}\right) v_{j}(x) d x\right) \\
& +\int_{\Omega}\left(D_{i}(x) \nabla u_{i}\left(x, t_{n}\right)+\frac{z_{i} F}{R T} \nabla \phi(x) u_{i}\left(x, t_{n}\right)\right) \\
& \nabla v_{j}(x) d x=\int_{\Omega} u_{i}\left(x, t_{n-1}\right) v_{j}(x) d x, \forall v_{j} \in \mathrm{H}_{1}(\Omega)
\end{aligned}
$$

The implementation of finite elements makes use of the deal.II library (20). Further details of the implementation may be found in (21).

With the cells of the different phases predefined with initial concentrations in the voxels, the aggressive solution is added by specifying Dirichlet boundary conditions (meaning fixing a constant concentration on the boundary), simulating that the model sample at hand is placed in an equilibrated reservoir of ammonium nitrate. Initially no reaction product is present inside the matrix.

The reaction equation is implemented on the basis functions of the transport equations, by comparing and computing the reaction between the respective concentration coefficients wherever portlandite is present. A backward reaction does not need to be calculated due to the separation from equilibrium.

\section{TESTING OF THE SOFTWARE}

Two cement matrices with $\mathrm{C} / \mathrm{S}=2$ were created to test the new software. The specimens were cubic with a size of $20 \mu \mathrm{m}$. This size was considered to be representative of the matrix because it is larger than its largest features, generally clinker grains. In ordinary Portland cements with a characteristic strength of $52.5 \mathrm{MPa}$, the majority of clinker grains are smaller than $20 \mu \mathrm{m}$. The pastes were prepared at a water to cement ratio of 0.3. Curing times were approximately 28 and 90 days. The phase distribution of the two matrices is summarized in Table 1. As expected, the increase in the curing time resulted in an increment of the amount of hydration products and a reduction of the capillary porosity. The obtained structures were then divided in voxels so that each $0.5 \mu \mathrm{m}$ voxel consisted solely of one of the following phases: pore solution, portlandite $(\mathrm{CH})$, IP-CSH, OP-CSH, OL-CSH or unhydrated clinker (CK). Figure.1 shows one of such structures at the initial stages of the degradation process.

As can be observed, each phase is represented by a colour that may change as a consequence of the degradation. In particular, portlandite and clinker transform into pore space and degraded C-S-H respectively when they degrade. As a consequence, they have to end up acquiring the colour of the new phase in order to reflect this change. On the contrary, the three C-S-H phases maintain their colour in spite of the calcium loss but with clearer tones as they lose calcium. This pretends to represent that $\mathrm{C}-\mathrm{S}-\mathrm{H}$ phases are always $\mathrm{C}-\mathrm{S}-\mathrm{H}$ independently of their calcium content.

The main inputs of the degradation code, in addition to the microstructure of the matrix, are the density, initial calcium concentration and initial porosity of each phase. In this case, all C-S-H varieties were assumed to have an initial value of calcium to silicon ratio of 1.7 while in the case of the CK this value increased up to 2 . It is also necessary to set the number of time-steps and time step size which passes in each transport step. Since chemical reactions are assumed to be instantaneous, the conversion from time-steps to real time can be made by means of the diffusion coefficient. In this case each time-step corresponds to $0.05 \mathrm{~s}$. Figure 2 shows a section of the matrix for the two curing times employed, 28 days (top) and 90 days (bottom), and their subsequent evolution along the degradation time (T).

Comparison between the top and bottom images makes evident the presence of lighter colours in the younger specimen (top) than in the older one (bottom). Since darker colours indicate higher calcium content than the lighter ones, this means that the top specimen was degraded to a greater extent by 
TABLE 1. Volumetric composition of the matrices

\begin{tabular}{lcccccc}
\hline Matrix & CH (\%) & CK (\%) & IP-CSH (\%) & OP-CSH (\%) & OL-CSH (\%) & Pore (\%) \\
\hline 28 days & 3 & 41 & 12 & 18 & 1 & 25 \\
90 days & 5 & 34 & 19 & 28 & 6 & 8 \\
\hline
\end{tabular}

the surrounding ammonium nitrate solution. This can be attributed to its greater capillary porosity (blue colour) that facilitates the diffusion processes. However, as can be observed in Figure 3a, the difference is very small on average.

From this point on, the discussion will focus exclusively on the results obtained for the 90 days

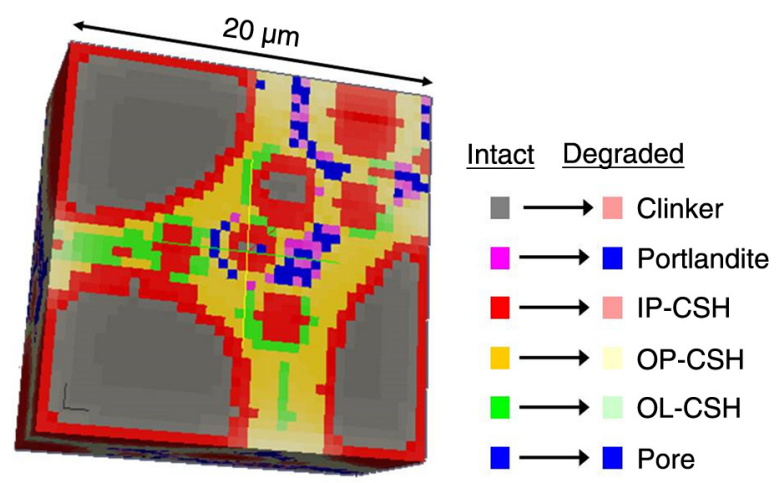

FIGURE 1. Example of hydrated cement paste at the initial stages of the degradation process. Each phase is represented by a colour (Clinker: grey; Portlandite: pink; IP-CSH: red; OP-CSH: yellow; OL-CSH: green; Pores: blue). The colours of the three C-S-H phases become lighter as they lose calcium. On the contrary, portlandite and clinker acquire the colour of Pores (blue) and IP-CSH (red) when they degrade to represent the phase transformation. old specimen. However, the conclusions apply also to the other specimen as well because it gave very similar results, see Figure 3a. Figure 3b shows the evolution of the calcium loss of the cement hydrates in comparison to the average value of the whole sample. In overall, the obtained results are in good agreement with the available literature (22-24); although, there are some details that might need clarification. As expected, cement hydrates degraded considerably faster than the clinker. On the contrary, Figure $3 \mathrm{~b}$ shows that the degradation rate of both portlandite and the C-S-H gel are very similar while it is well known that this is not the case (22-24). The difference arises from the fact that in experimental works no distinction is made between the gel formed before the degradation process and that resulting from the simultaneous degradation and hydration of the clinker. If the hydrating/ degrading clinker phase were considered as C-S-H gel it would be evident that the degradation rate of portlandite would be much faster than the combined rate for the CK and C-S-H phases in Figure $3 \mathrm{~b}$, in good agreement with the experiments (22-24). Another point that should be clarified is that in Figure 2 the loss of calcium from the clinker and IP-CSH is present from the very beginning of the degradation process. Under natural conditions these phases should be initially protected by the layer of hydration products surrounding it. However, as can

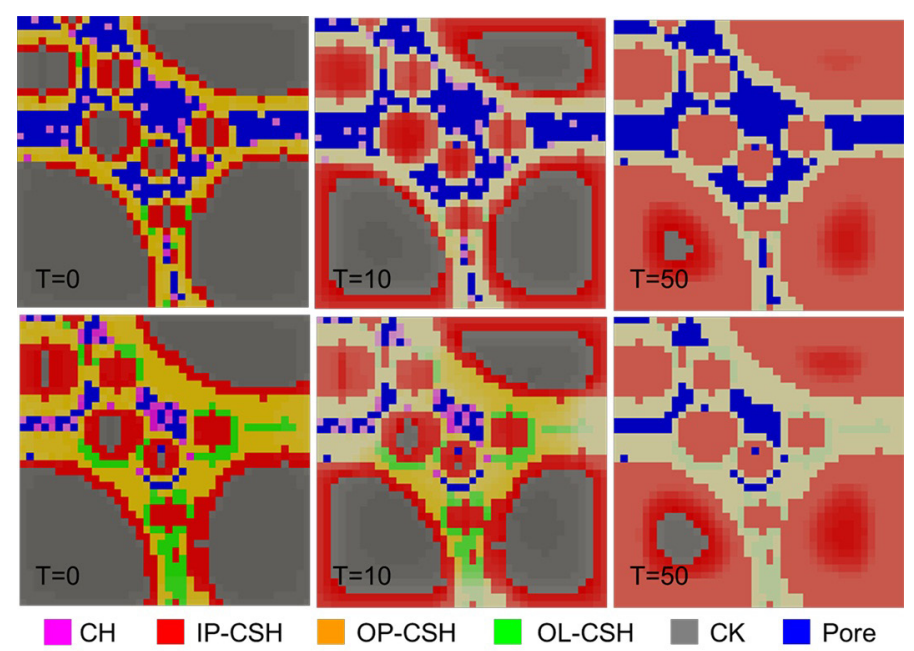

Figure 2. Middle section of the 28 days (top) and 90 days (bottom) matrices at different degradation times (T). For each particular colour clearer tones indicate smaller calcium content than the darker ones. 

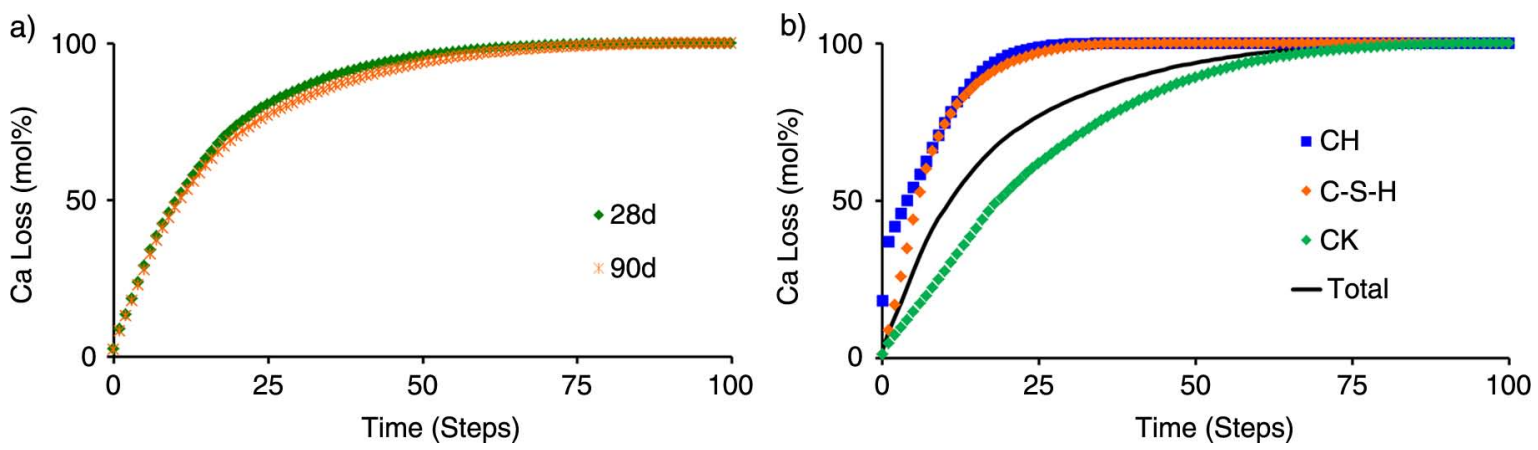

Figure 3. a) Average calcium loss of the two specimens as a function of the degradation time. b) Evolution of the calcium loss by the main phases of the 90 days specimen in comparison to the integrated curve.

be observed in Figure 1 and Figure 2, the studied structures have been obtained by cutting them from larger structures. As a consequence, some clinker grains and IP-CSH particles have been cut, leaving their inside directly exposed to the aggressive solution. Although the effect of surface voxels is very small due to their small amount compared to the total number of voxels of the sample, this problem was overcome by repeating the experiment but covering with an impenetrable shell the whole matrix except the external pores. As expected, no significant difference was observed further than a slight delay in the degradation of the IP-CSH and specially the clinker.

Although calcium concentration is the magnitude that governs the whole degradation process, the magnitudes of interest from an engineering point of view are the porosity and the elastic modulus. Figure 4 shows the contribution of each particular phase to the total porosity of the 90 days specimen.

As can be observed, initially the whole contribution to the porosity comes from the C-S-H gel and the capillary porosity. As the degradation begins the contribution of the C-S-H gel becomes even larger because the contributions of portlandite and the clinker are very small. This is due to the small proportion of the former and due to the assumption that the clinker can initially degrade without a porosity increase. Only once the C-S-H is exhausted does the contribution of the clinker become really relevant, being the sole responsible of the porosity increase for much of the degradation process after the early period. It is evident that this is motivated by the low initial hydration degree of the matrix, with more than half of its volume initialy occupied by unhydrated cement. As can be observed in Figure 5a, the contribution of the different phases to the total gel porosity is given by the initial relative proportions of each of them. Therefore, the smallest contribution comes from the OL-CSH followed by the IP-CSH and finally the OP-CSH. There is little difference between the times at which each of them degrades. This was attributed to the small volume of the OP-CSH and OL-CSH. At the beginning of the degradation process, IP-CSH is protected by a shell of OP-CSH and OL-CSH. However, since there is not much of these phases, they are soon consumed at some places beginning to leave the IP-CSH exposed. The range of values of the total porosity of the paste is in good agreement with the findings of Chen et al. (25).

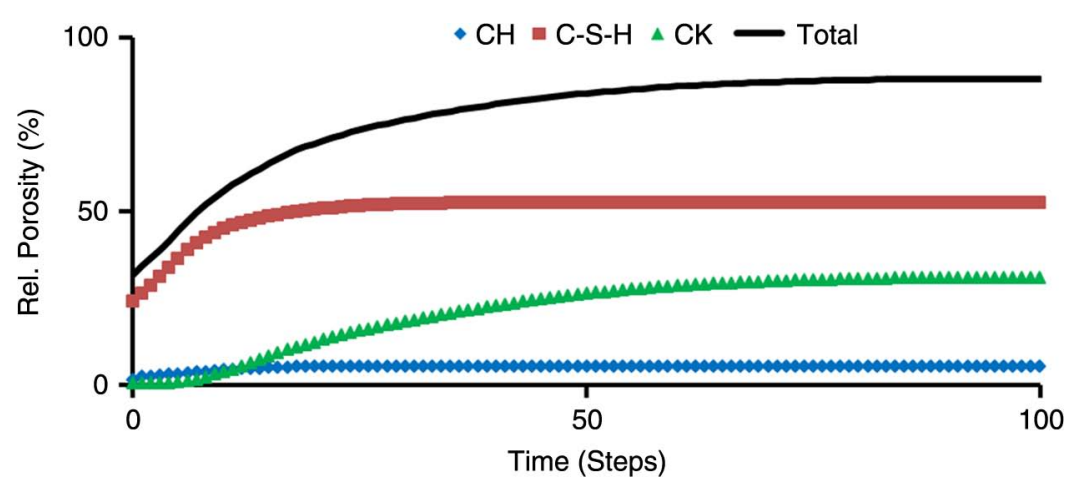

Figure 4. Evolution of the contribution of the main hydrates (CH: Portlandite, C-S-H: C-S-H gel, CK: unhydrated clinker) to the porosity. 

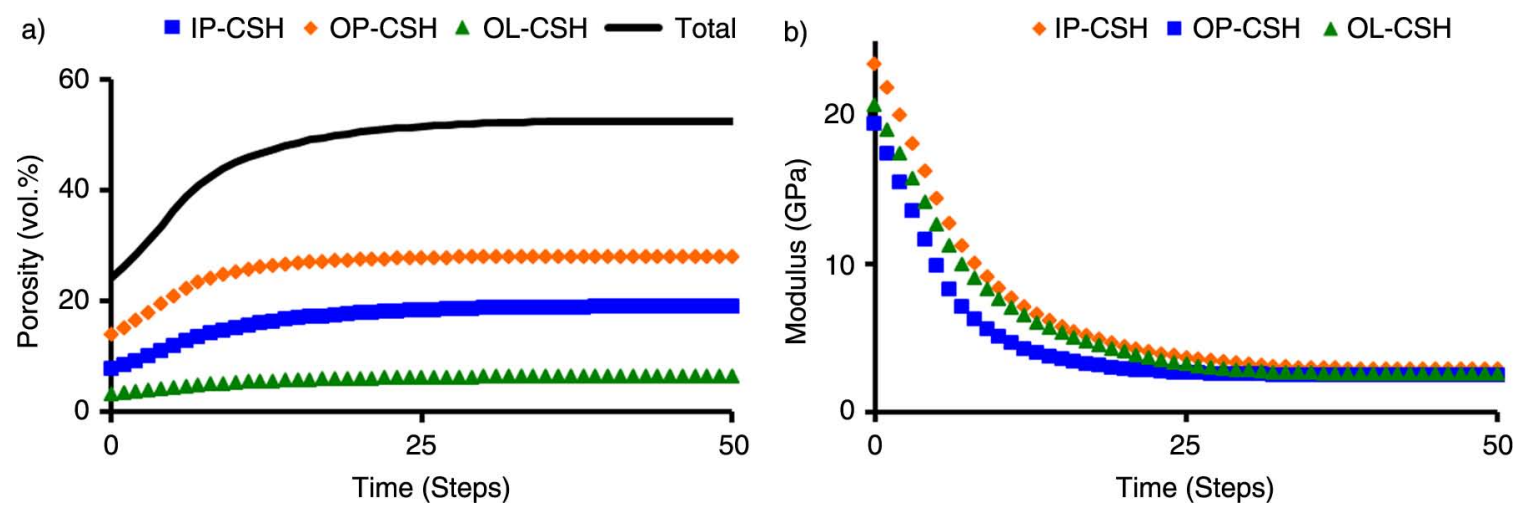

FIGURE 5. a) Porosity contribution of each clinker phase to the gel porosity. b) Evolution of the elastic modulus of the three phases of the C-S-H gel along the degradation process.

The elastic modulus of each of the three C-S-H phases was calculated using Mori-Tanaka's approximation (25), assuming that $\mathrm{C}-\mathrm{S}-\mathrm{H}$ voxels are made of porous Tobermorite $14 \AA$ (26-27). As a consequence, the time evolution is given by the time evolution of the porosity, see Figure 5a and Figure 5b.

As can be observed in Figure 5b, OP-CSH degrades slightly faster than the other two phases. In order to compare with the experimental values available in the literature $(23,28-34)$, it is more appropriate to plot the elastic modulus as a function of the C/S, see Figure 6 .

All the experimental values included in Figure 6 are also presented in Table 2 . In the figure, all undegraded samples have been assumed to have $\mathrm{C} / \mathrm{S}=2$, in order to ease visual comparison. However, it is worth saying that the results contained in Table 2 show no influence in the C/S of the paste, as far as, this is undegraded. This is so because the C-S-H gel of all undegraded samples has a similar $\mathrm{C} / \mathrm{S}$ being other phases like portlandite which

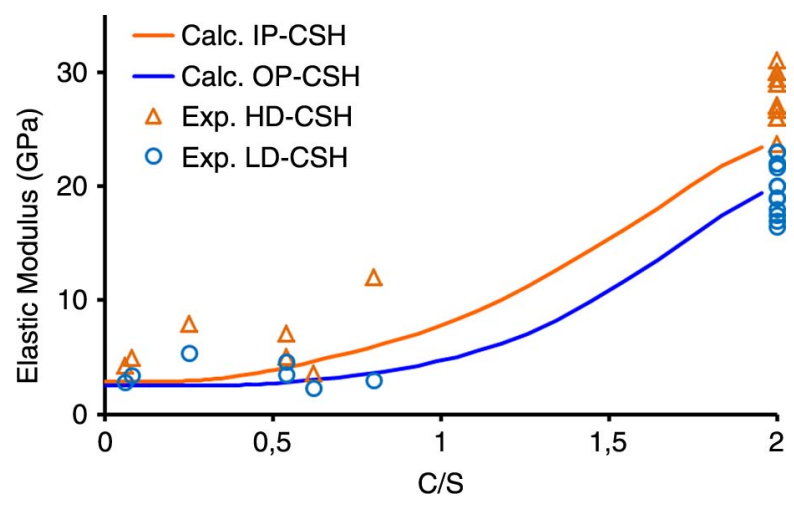

FiguRE 6. Experimental and calculated values for the elastic modulus as a function of the C/S of the cement paste. In order to ease comparison, all undegraded samples have been assumed to have $\mathrm{C} / \mathrm{S}=2$ independently of their composition, see Table 2 and references $(23,29-35)$. are affected by the smaller proportion of calcium. As can be observed in Figure 6, prior to the beginning of the degradation $(\mathrm{C} / \mathrm{S}=2)$, the value of the modulus of the OP-CSH is in very good agreement with the reported values for the low density C-S-H (LD-CSH). Similarly, the result obtained in this work for the IP-CSH falls within the range of values presented in the literature for the high density C-S-H (HD-CSH), although it is clearly smaller than the average. It is worth stressing the large scattering of the results available in the literature compared to the low dispersion of the results presented by some authors. This might be related to the difficulty of sample preparation and to the lack of a standard procedure for doing so. This problem is even more severe in the degraded samples which, in addition of being much weaker and therefore more difficult to handle, include the uncertainty of the determination of the C/S. All results contained in Table 2 and Figure 6 have been obtained in asymptotically leached samples. As a consequence, little if any variation should be observed in the values of the C/S and elastic modulus as a function of the distance to the exposed surface. The obtained results are in good agreement with the experimental ones for $\mathrm{C} / \mathrm{S}$ larger than 0.5 ; for $\mathrm{C} / \mathrm{S}$ smaller than 0.5 there is an underestimation of the calculated elastic modulus that is more important in the case of the IP-CSH.

\section{CONCLUSIONS}

A set of tools for the simulation of calcium leaching of the cement paste has been developed and tested. Such tools provide information about the effect of the degradation process on individual phases at the level of the nano-/microscale. Comparison with the experimental results available in the literature showed good agreement for the evolution of the elastic modulus of the C-S-H gel along the degradation process. Only when the 
TABLE 2. Experimental values of the elastic modulus of the C-S-H gel (GPa) obtained from the literature $(23,29-35)$. $\mathrm{C} / \mathrm{S}$ of the paste is also provided for the degraded samples

\begin{tabular}{|c|c|c|c|c|c|c|}
\hline \multirow[b]{2}{*}{ Reference } & \multirow[b]{2}{*}{ Material } & \multicolumn{2}{|c|}{ Undegraded } & \multicolumn{3}{|c|}{ Degraded } \\
\hline & & LD-CSH & HD-CSH & $\mathrm{C} / \mathrm{S}$ & LD-CSH & HD-CSH \\
\hline (23) & OPC & $22 \pm 2$ & $29 \pm 2$ & 0.8 & $3.0 \pm 0.8$ & $12 \pm 1$ \\
\hline (29) & OPC & $19 \pm 3$ & $27 \pm 4$ & 0.62 & $2.3 \pm 0.5$ & $3.6 \pm 0.6$ \\
\hline (29) & $\mathrm{OPC}+6 \% \mathrm{NS}^{\mathrm{i}}$ & $23 \pm 2$ & $27 \pm 3$ & 0.54 & $3.5 \pm 0.7$ & $5 \pm 0.9$ \\
\hline (29) & OPC & $26 \pm 4$ & $34 \pm 3$ & 0.24 & $5 \pm 1$ & $8 \pm 1$ \\
\hline (29) & White OPC & $21 \pm 3$ & $33 \pm 3$ & 0.06 & $2.8 \pm 0.8$ & $4.3 \pm 0.6$ \\
\hline$(30-31)$ & $\mathrm{C}_{3} \mathrm{~S} / \mathrm{C}_{2} \mathrm{~S}^{\mathrm{ii}}$ & $25 \pm 3$ & $32 \pm 4$ & 0.08 & $3.4 \pm 0.6$ & $5 \pm 1$ \\
\hline$(30-31)$ & $\mathrm{C}_{3} \mathrm{~S} / \mathrm{C}_{2} \mathrm{~S}^{\mathrm{iii}}$ & $22 \pm 4$ & $30 \pm 4$ & & & \\
\hline$(30-31)$ & $\mathrm{C}_{3} \mathrm{~S}$ & $23 \pm 3$ & $30 \pm 4$ & & & \\
\hline$(30-31)$ & $\mathrm{C}_{2} \mathrm{~S}$ & $22 \pm 4$ & $27 \pm 5$ & & & \\
\hline (32) & Ductal & $20 \pm 2$ & $30 \pm 4$ & & & \\
\hline (33) & OPC & $16 \pm 5$ & $27 \pm 4$ & & & \\
\hline (33) & $\mathrm{OPC}+15 \% \mathrm{SF}^{\mathrm{iv}}$ & $17 \pm 4$ & $26 \pm 3$ & & & \\
\hline$(29,33-34)$ & $\mathrm{OPC}+6 \% \mathrm{NS}^{\mathrm{v}}$ & $17 \pm 1$ & $23.7 \pm 0.4$ & & & \\
\hline$(29,33-34)$ & $\mathrm{OPC}+18 \% \mathrm{NS}^{\mathrm{v}}$ & $18.9 \pm 0.4$ & $26.7 \pm 0.8$ & & & \\
\hline (35) & White OPC & $18 \pm 4$ & $29 \pm 4$ & & & \\
\hline
\end{tabular}

iOPC paste containing $6 \mathrm{wt} . \%$ of nanosilica powder.

${ }^{\text {ii Mii }}$ Mixture of pure $\mathrm{C}_{3} \mathrm{~S}$ and $\mathrm{C}_{2} \mathrm{~S}$ in a weight fraction $70: 30$.

iii Mixture of pure $\mathrm{C}_{3} \mathrm{~S}$ and $\mathrm{C}_{2} \mathrm{~S}$ in a weight fraction 30:70.

${ }^{\text {iv }} \mathrm{OPC}$ paste containing $15 \mathrm{wt} . \%$ of silica fume.

${ }^{v}$ OPC paste containing 6 or $18 \mathrm{wt} . \%$ of colloidal nanosilica.

$\mathrm{C} / \mathrm{S}$ of the paste fell below 0.5 , an underestimation of the predicted values was observed. The values of the total porosity of the paste before and after calcium leaching are similar to those reported on the literature. On the contrary, in this work, no significant difference was observed between the degradation rate of portlandite and the C-S-H gel. However, this was attributed to the fact that in the literature no distinction is made between the C-S-H gel formed before and along the degradation process. Finally, the obtained results indicate that the contribution of each phase to the total porosity of the paste depends mainly in their volumetric proportion within the matrix.

Although the matrix studied consisted of two belite cements mixed at a water to cement ratio of 0.3 and cured for 28 and 90 days respectively, the model does not impose any limitations on any of these parameters. The employed aggressive solution was $6 \mathrm{M}$ ammonium nitrate but any other solution could also be employed with minor modifications of the degradation program. Accordingly, the number of species present in the pore solution was limited but the software is very flexible in this aspect. Finally, the number of cement hydrates considered was reduced to portlandite, unhydrated clinker and the three types of C-S-H, although the program allows the introduction of more phases as long as calcium concentration, porosity and diffusion coefficient are provided. Aggregates or reinforcements can also be easily included.

\section{ACKNOWLEDGMENTS}

The authors would like to acknowledge the financial support from the European Commission as part of the project: Computationally driven design of innovative cement-based materials "CODICE" (CP-FP 214030-2).

\section{REFERENCES}

1. Carde, C.; Francois, R.; Torrenti, J.M. (1996) Leaching of both calcium hydroxide and C-S-H from cement paste: modeling the mechanical behaviour. Cem. Concr. Res. 26 [8], 1257-1268. http://dx.doi.org/10.1016/0008-8846(96)00095-6.

2. Nguyen, V.H.; Colina, H.; Torrenti, J.M.; Boulay, C.; Nedjar, B. (2007) Chemo-mechanical coupling behaviour of leached concrete: Part I: Experimental results. Nucl. Eng. Des. 237 [20-21], 2083-2089. http://dx.doi.org/10.1016/j. nucengdes.2007.02.013.

3. Barbarulo, R.; Marchand, J.; Zinder, K.A.; Prené, S. (2000) Dimensional analysis of ionic transport problems in hydrated cement systems. Part 1. Theoretical considerations. Cem. Concr. Res. 30 [12], 1955-1960. http://dx.doi. org/10.1016/S0008-8846(00)00383-5.

4. Mainguy, M.; Coussy, O. (2000) Propagation fronts during calcium leaching and chloride penetration. J. Eng. Mech. 126 [3], 250-257. http://dx.doi.org/10.1061/(ASCE) 0733-9399(2000)126:3(250). 
5. Mainguy, M.; Tognazzi, C.; Torrenti, J.M.; Adenot, F. (2000) Modelling of leaching in pure cement paste and mortar. Cem. Concr. Res. 30 [1], 83-90. http://dx.doi.org/ 10.1016/S0008-8846(99)00208-2.

6. Ulm, F-J.; Torrenti, J.M.; Adenot, F. (1999) Chemoporoplasticity of calcium leaching in concrete. J. Eng. Mech. 125 [10], 1200-1211. http://dx.doi.org/10.1061/(ASCE) 0733-9399(1999)125:10(1200).

7. Adenot, F.; Buil, M. (1992) Modeling of the corrosion of cement paste by deionized water. Cem. Concr. Res. 22 [2-3], 489-496. http://dx.doi.org/10.1016/0008-8846(92)90092-A.

8. Bentz, D.P.; Garboczi, E.J. (1992) Modelling the leaching of calcium hydroxide from cement paste: effects on pore space percolation and diffusivity. Mater. Struct. 25 [9], 523533. http://dx.doi.org/10.1007/BF02472448.

9. Gérard, B.; Le Bellego, C.; Bernard, O. (2002) Simplified modelling of calcium leaching of concrete in various environments. Mater. Struct. 35 [10], 632-640. http://dx.doi.org/ $10.1007 / \mathrm{BF} 02480356$

10. Nguyen, V.H.; Nedjar, B.; Torrenti, J.M. (2007) Chemomechanical coupling behaviour of leached concrete: Part II: Modelling. Nucl. Eng. Des. 237 [20-21], 2090-2097. http://dx.doi.org/10.1016/j.nucengdes.2007.02.012.

11. Nakarai, K.; Ishida, T.; Maekawa, K. (2006) Modeling of calcium leaching from cement hydrates coupled with micropore formation. J. Adv. Concr. Technol. 4 [3], 395-407. http://dx.doi.org/10.3151/jact.4.395.

12. Gawin, D.; Pesavento, F.; Schrefler, B.A. (2009) Modeling deterioration of cementitious materials exposed to calcium leaching in non-isothermal conditions. Comput. Method Appl. M. 198 [37-40], 3051-3083. http://dx.doi. org/10.1016/j.cma.2009.05.005.

13. Gawin D.; Pesavento, F. Schrefler, B.A. (2008) Modeling of cementitious materials exposed to isothermal calcium leaching, considering process kinetics and advective water flow. Part 1: Theoretical model. Comput. Methods App. M. 45 [25-26], 6221-6240. http://dx.doi.org/10.1016/j.ijsolstr.2008.07.010.

14. Berner, U.R. (1998) Modeling the incongruent dissolution of hydrated cement materials. Radiochim. Acta. 4445 [2], 387-393. http://www.degruyter.com/view/j/ract.1988.44-45. issue-2/ract.1988.4445.2.387/ract.1988.4445.2.387.xml

15. Van Breugel, K. (1995) Numerical simulation of hydration and microstructural development in hardening cementbased materials (I) theory. Cem. Comcr. Res. 25 [2], 319331. http://dx.doi.org/10.1016/0008-8846(95)00017-8

16. Richardson, I.G.; Groves, G.W. (1992) Models for the composition and structure of calcium silicate hydrate (C-S-H) gel in hardened tricalcium silicate pastes. Cem. Concr. Res. 22 [6], 1001-1010. http://dx.doi.org/10.1016/ 0008-8846(92)90030-Y.

17. Cong, X.D.; Kirkpatrick, R.J. (1996) ${ }^{29}$ MAS NMR study of the structure of calcium silicate hydrate. Adv. Cem. Based Mater. 3 [3-4], 144-56. http://dx.doi.org/10.1016/ S1065-7355(96)90046-2.

18. Fuji, K.; Kondo, W. (1983) Estimation of thermochemical data for calcium silicate hydrate (C-S-H). J. Am. Ceram. Soc. 66 [12], 220-221. http://dx.doi.org/10. 1111/j.1151-2916.1983.tb11011.x.

19. Li, Y-H.; Gregory, S. (1974) Diffusion of ions in sea water and in deep-sea sediments. Geochim. Cosmochim. Ac. 38 [5], 703-714. http://dx.doi.org/10.1016/0016-7037(74)90145-8.

20. Bangerth, W.; Hartmann, R.; Kanschat, G. (2007) deal. II-A general-purpose object-oriented finite element library. ACM Trans. Math. Softw. 33 [4], 24/1-24/27. http://dx.doi. org/10.1145/1268776.1268779.
21. Neuen, C. (2010) Ein multiskalenansatz zur Poisson-NernstPlanck gleichung (A multiscale approach to the PoissonNernst-Planck equation). Diplomathesis. University of Bonn, Bonn (2010). http://wissrech.ins.uni-bonn.de/teaching/ diplom/diplom_neuen.pdf.

22. Gaitero, J.J.; Campillo, I.; Guerrero, A. (2008) Reduction of the calcium leaching rate of cement paste by addition of silica nanoparticles. Cem. Concr. Res. 38 [8-9], 1112-1118. http://dx.doi.org/10.1016/j.cemconres.2008.03.021

23. Constantinides, G.; Ulm, F-J. (2004) The effect of two types of C-S-H on the elasticity of cement-based materials: results from nanoindentation and micromechanical modelling. Cem. Concr. Res. 3 [1], 27-80. http://dx.doi.org/ 10.1016/S0008-8846(03)00230-8

24. Heukamp, F.H.; Ulm, F-J.; Germaine, J.T. (2001) Poroplastic properties of calcium leached cement-based materials. Cem. Concr. Res. 33 [8], 1155-1173. http://dx.doi. org/10.1016/S0008-8846(03)00024-3.

25. Chen, J.J.; Thomas, J.J.; Jennings, H.M. Preparation of single-phase C-S-H specimens from hydrated tricalcium silicate pastes. http://www.civil.northwestern.edu/people/ thomas/pdf/Chen_CSHPrep_CCR_sub.pdf

26. Mori, T.; Tanaka, K. (1973) Average stress in matrix and average elastic energy of materials with misfitting inclusions. Acta Metall. Mater 21 [5], 571-574. http://dx.doi. org/10.1016/0001-6160(73)90064-3.

27. Manzano, H.; Dolado, J.S.; Ayuela, A. (2009) Elastic properties of the main species present in Portland cement pastes. Acta Mater. 57 [5], 1666-1674. http://dx.doi.org/10.1016/j. actamat.2008.12.007.

28. Manzano, H.; Dolado, J.S.; Guerrero, A.; Ayuela, A. (2007) Mechanical properties of crystalline calciumsilicate-hydrates: comparison with cementitious C-S-H gels. Phys. Status Solidi A. 204 [6], 1775-1780. http://dx.doi. org/10.1002/pssa.200675359.

29. Gaitero, J.J. (2008) Multi-scale study of the fibre-matrix interface and calcium leaching in high performance concrete. Ph.D. thesis. University of the Bask Country (UPVEHU), Bilbao (2008). http://www.mendeley.com/profiles/ jon-gaitero/publications/journal.

30. Project COmputationally Driven design of Innovative Cement-based materials (CODICE). CP-FP 214030-2. Final report.

31. Goñi, S.; Guerrero, A.; Puertas, F.; Hernández, M.S.; Palacios, M.; Dolado, J.S.; Zhu, W.; Howind, T. (2011) Textural and mechanical characterization of C-S-H gels from hydration of synthetic T1-C3S, $\beta-\mathrm{C} 2 \mathrm{~S}$ and their blends. Mater. Construcc. 61 [302], 169-183. http://dx.doi. org/10.3989/mc.2011.00511.

32. Acker, P. (2001) Micromechanical analysis of creep and shrinkage mechanisms. Topical keynote lecture in "Shrinkage and durability mechanics of concrete and other quasi-brittle materials", Elsevier, (2001).

33. Mondal, P.; Shah, S.P.; Marks, L.D.; Gaitero, J.J. (2010) Comparative study of the effects of microsilica and nanosilica in concrete. Transp. Res. Rec. [2141], 6-9. http:// dx.doi.org/10.3141/2141-02.

34. Gaitero, J.J.; Campillo, I.; Mondal, P.; Shah, S.P. (2010) Small changes can make a great difference. Transp. Res. Rec. [2141], 1-5. http://dx.doi.org/10.3141/2141-01.

35. Constantinides, G.; Ulm, F-J. (2007) The nanogranular nature of C-S-H. J. Mech. Phys. Solids. 55 [1], 64-90. http:// dx.doi.org/10.1016/j.jmps.2006.06.003. 